\title{
Short implants to support mandibular complete dentures - photoelastic analysis
}

\author{
Marcele Jardim PIMENTEL (a) \\ Wander José da SILVA(a) \\ Altair Antoninha DEL BEL CURY(a)
}

(a) Universidade de Campinas - UNICAMP, Piracicaba Dental School, Department of Prosthodontics and Periodontology,

Piracicaba, SP, Brazil.
Declaration of Interests: The authors certify that they have no commercial or associative interest that represents a conflict of interest in connection with the manuscript.

\section{Corresponding Author:}

Marcele Jardim Pimentel

marcelejardim@gmail.com

htpp://doi.org/10.1590/1807-3107BOR-2017.vol31.0018

Submitted: Feb 13, 2016

Accepted for publication: Nov 21, 2016

Last revision: Dec 12, 2016
Abstract: This study evaluated the stress behavior around short implants in edentulous atrophic mandibles. Six groups included implants with two diameters regular and wide $(4$ and $5 \mathrm{~mm})$ and three lengths (5, 7 and $9 \mathrm{~mm})$ as follows: Ci9 $(9 \times 4 \mathrm{~mm}), \mathrm{Ci} 7(7 \times 4 \mathrm{~mm}), \mathrm{Ci} 5$ (5 $44 \mathrm{~mm}), \mathrm{Wi} 9(9 \times 5 \mathrm{~mm}), \mathrm{Wi} 7(7 \times 5 \mathrm{~mm})$ and Wi5 $(5 \times 5 \mathrm{~mm})$. These groups were compared to the control group CG $(11 \times 4 \mathrm{~mm})$. The analysis was performed with the photoelastic method $(n=6)$. Each model comprised 4 implants with the same length and diameter connected by a chromium-cobalt bar that simulates a fixed denture. A $0.15 \mathrm{~kg}$ force was applied at the end of the cantilever $(15 \mathrm{~mm})$, and the maximum shear stress was recorded around the distal and subsequent implants. The stress values were determined, and the quantitative data (Fringes ${ }^{\circledR}$ ) were submitted to statistical analysis with one-way ANOVA and the Dunnett test $(p<0.05)$. It was observed that the reduction in implant length increased stress values with a significant difference $(p<0.05)$ between CG Ci7 and Ci5, while the increase in implant diameter reduced the stress values without any differences found between short and long implants. Implants with 5 and $7 \mathrm{~mm}$ with regular diameter increased stress levels while short implants with larger diameters experienced similar stress to that of longer implants.

Keywords: Dental Implants; Bone Resorption; Denture, Complete.

\section{Introduction}

Severe alveolar bone resorption is of great concern for oral rehabilitation. ${ }^{1,2}$ Progressive bone loss can restrict the use of implants; many are the surgical approaches to overcome this condition. ${ }^{3,4}$ Short implants $(<10 \mathrm{~mm})$ have been proposed as an alternative to the long ones in an attempt to avoid some surgical procedures such as bone grafting. In addition, they also reduce the morbidity, treatment time, costs and complications rates. $5,6,7,8,9,10$

Initially, short implants had a standard diameter $(3.75 \mathrm{~mm})$, received no surface treatment, and present preponderant failures rates. ${ }^{11,12,13}$ Recent studies have shown positive results for short implants ${ }^{1,8,14,15,16}$ even for those shorter than $7 \mathrm{~mm}$ in length. ${ }^{78,9,17}$. Clinical studies have also shown that short implants are preferred over long implants associated with extensive reconstructive procedures $7,9,10,18$. Higher implant failure and more complications have been reported for patients undergoing bone graft, 
to receive long implants, when compared to those receiving short implants only. ${ }^{79,17,19}$ In 20-year follow up study, no implant fractures or complications have been found for short implants $(8 \mathrm{~mm}){ }^{15}$

Systematic reviews also reported that short implants can be placed successfully in the partially edentulous patient. ${ }^{13,20,21,22,23}$ Implants shorter than $10 \mathrm{~mm}$ are sufficient to support occlusal forces without undesirable crestal bone resorption, even when restored with an unsplinted single-crown. ${ }^{8}$ Currently the increasing survival rates of the short implants are associated with improvement in the surface of implants. The cumulative success of rough-surface implants is greater than that of machined-surface implants, especially for short implants. ${ }^{21,23,24}$ Moreover, the increase in the diameter of implants could help minimize complications s,25,26 $^{125}$ since a large implant diameter might result in more homogeneous stress distribution and less stress concentration on the implants. ${ }^{27}$

Most studies with short implants involve partially edentulous patients or those who require a single tooth replacement. Few authors report cases with short implants in totally edentulous patients, with follow up from 2 to 10 years ${ }^{1,19,28}$ who might present with a progressive bone resorption, and, often a conventional removable denture might provide little or no stability and unsatisfactory results. In these cases, implant-supported prosthesis could be an optimal alternative. However the reduced support provided by short implants might increase the stress levels in severely atrophic mandible and requires caution. Therefore, the knowledge of the biomechanics of dentures supported by short implants is necessary to increase the predictability of this treatment and avoid complications. ${ }^{29}$ The substantial outcomes obtained with short implants conduced us to test the biomechanical behaviour of short implants when used to support complete prosthesis. This would contribute to the treatment planning involving patients with severe mandibular atrophy, to increase the predictability, and avoid large bone reconstructions. This study investigated the hypothesis that, when used to support a fixed prosthesis in the atrophic mandible, short implants might increase stress levels in the peri-implant area.

\section{Methodology}

This in vitro study was conducted using the photoelastic analysis. Implants were assigned to 6 experimental groups (Table 1 ) according to their lengths $(5,7$, and $9 \mathrm{~mm})$ and diameters (4 and $5 \mathrm{~mm})$. A longer implant $(11 \mathrm{~mm})$ was used as the control. Each group contained four Morse taper implants (Titamax CM or Titamax WS; Neodent) with their respective mini conical abutment (height $1.5 \mathrm{~mm}$ ). The implants were named A, B, C, D from the loaded to the non-loaded side. A chromium-cobalt bar with a bilateral cantilever of $15 \mathrm{~mm}$ was attached to the implants.

\section{Photoelastic model development}

\section{Matrix development}

Photoelastic plane models were fabricated considering an average interforaminal distance of $40.35 \mathrm{~mm}$ obtained from a metric analysis involving twenty-three dissected resorbed mandibles. Such distance mean value was used to determine the spatial distribution of implants using computer software (SolidWorks; Dassault Systemes Solid Works Corp) (Figure 1). This distance value was set in the software (Figure 1A - red line) and a mandible image was imported to limit the anterior anatomy of the arch. The dimensions used to obtain the plane model were then determined (Figure 1 - blue line) following the curvature of the arc and the interforaminal distance. Based on these dimensions, a glass matrix for the photoelastic model was made

Table 1. Groups distribution in accordance with length and diameter.

\begin{tabular}{lcc}
\hline Group & Length $(\mathrm{mm})$ & Diameter $(\mathrm{mm})$ \\
\hline CG & 11.0 & 4.0 \\
Ci9 & 9.0 & 4.0 \\
Ci7 & 7.0 & 4.0 \\
Ci5 & 5.0 & 4.0 \\
Wi9 & 9.0 & 5.0 \\
Wi7 & 7.0 & 5.0 \\
Wi5 & 5.0 & 5.0 \\
\hline
\end{tabular}

CG: control group; $\mathrm{Ci}$ : conventional implant (4.0mm of diameter) Wi: wide implant ( $5.0 \mathrm{~mm}$ of diameter). 
with two plane arms (50 $\mathrm{mm}$ long each), with an angle of approximately $130^{\circ}$, a height of $20 \mathrm{~mm}$, and a thickness of $10 \mathrm{~mm}$.

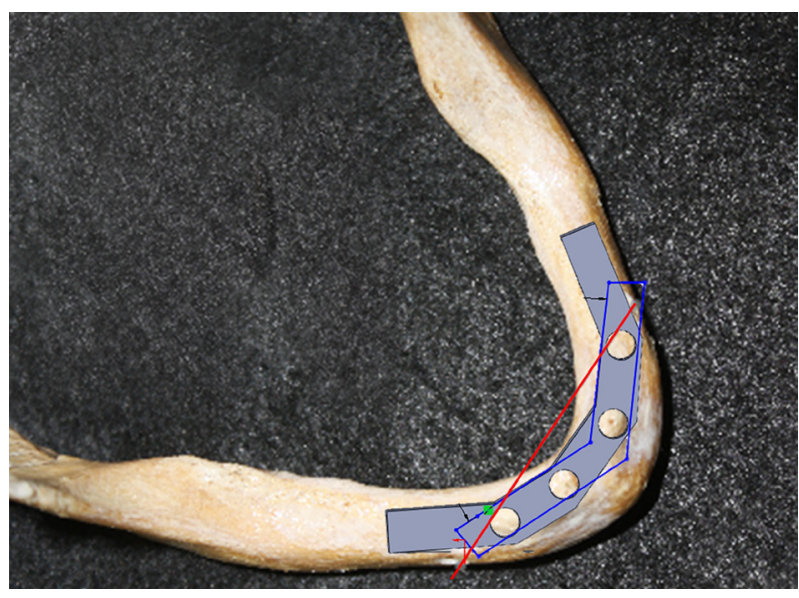

Figure 1. Interforaminal Distance $(40.35 \mathrm{~mm})$ represented by red line. Tridimensional distribution. The blue line represents the contour of the matrix.

\section{Master casts}

A polyvinyl siloxane impression was taken from a mandible (Figure 2A) and, based on the implant position defined in the software, an index was created to standardize the position of each analogue abutment (Figure 2B). One master cast was built with type IV stone (Figure 2C) and used to fabricate the cobalt-chromium frameworks.

\section{Photoelastic model manufacture}

The glass matrix was immersed in silicone (ABS blue; Polipox) for 4 hours to fabricate a silicone mold. The abutments and the framework were screwed in the implants before being submerged in the photoelastic resin, eliminating the possibility of stresses originated from the implant/framework interface (Figure 3A). An acrylic resin platform was used to connect this set (implants, abutments and bar) to a vertical device, fabricated to allow the suspension of the set within
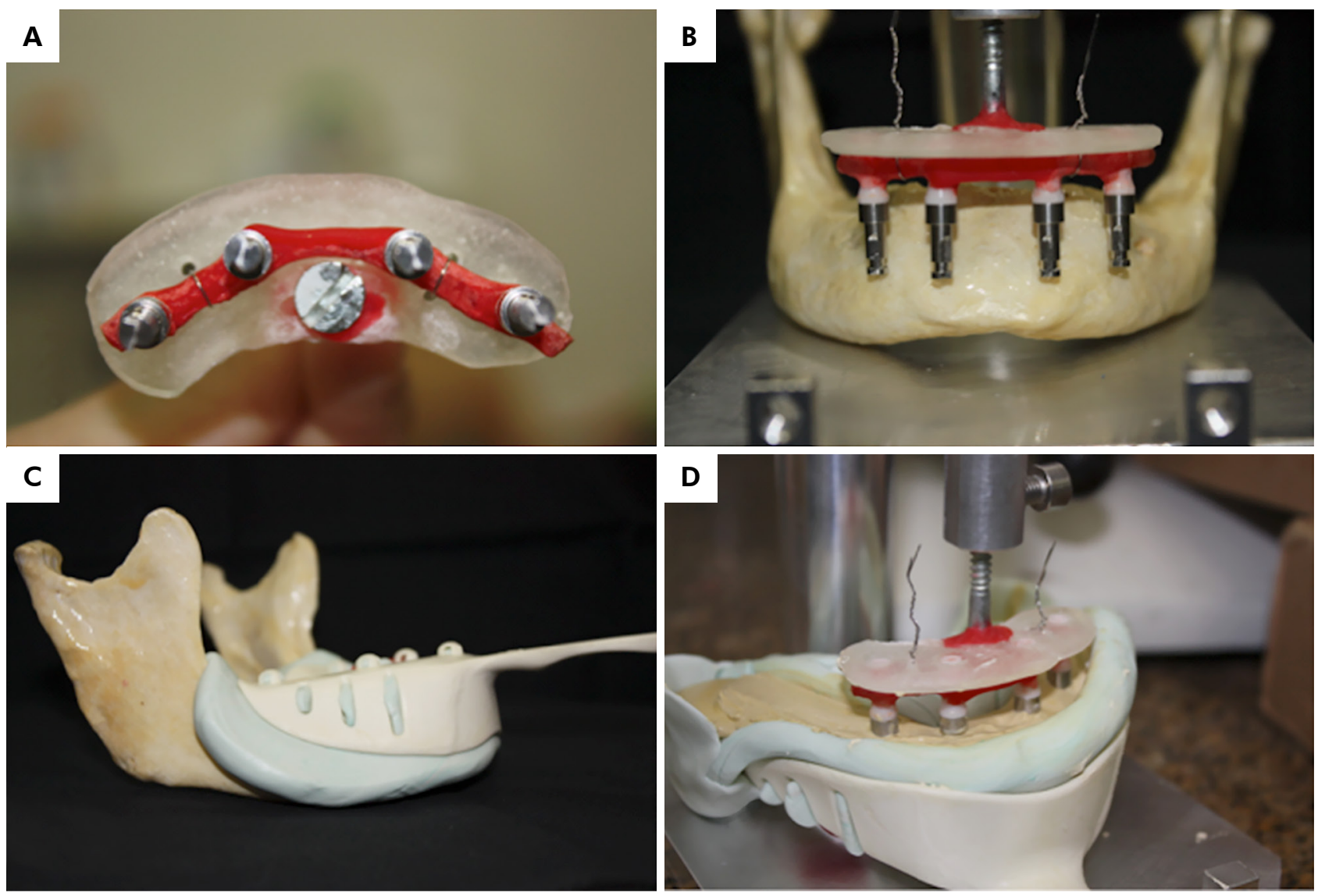

Figure 2. Sequence to bar confection: A) Jaw shaped B) Analogue distribution C) Bone impression D) Plaster cure. 
the silicone mold (Figure 3B). The vertical rod was manipulated to insert the implants in the exactly position into the mold (Figure 3C). The photoelastic resin (GIV; Polipox) was insert with a syringe until the resin reached implant platform. This set was stored in an air pressure chamber at 60 psi, for 10 minutes to eliminate seizure air molecules. The molds were submitted to photoelastic analysis 48 hours after the pressure exposure (Figure 3D). The definitive models were visually evaluated for smoothness and transparency, and also, were positioned in a circular polariscope (Federal University of Uberlandia, UFU) to confirm the absence of residual stress. After preliminary tests, in an attempt to simulate the atrophic bone, the specimen height was standardized to sufficient heights that avoid rotation of the specimen during the distal loading. A slit was made at the end of cantilever, to ensure that the load was applied at the same position for all infrastructures. Three photoelastic models composed each group, and were analyzed bilaterally $(\mathrm{n}=6) . "$

\section{Loading and analysis characteristic}

A load of $0.15 \mathrm{kgf}$ was applied at the end of the cantilever. The load value was determined in a pilot study, in order to limit the fringes formation until order 4, which allows the determination of the shear stress values.

The quantitative analysis was performed by Fringes software (Federal University of Uberlandia, UFU). Five-point readings were predetermined in the captured images at Fringes ${ }^{\circledR}$ software (two cervical and three apical), in which provided shear stress values, being the black color the lower value (Figure 4).

For the statistical analysis, all the the groups (Ci9, Ci7, Ci5, Wi9, Wi7 and Wi5) were compared to the control group (CG, 11x4mm impant) by means of the One-way ANOVA followed by Dunnett's test $(\mathrm{p}<0.05)($ SAS - Statistical Analysis System).
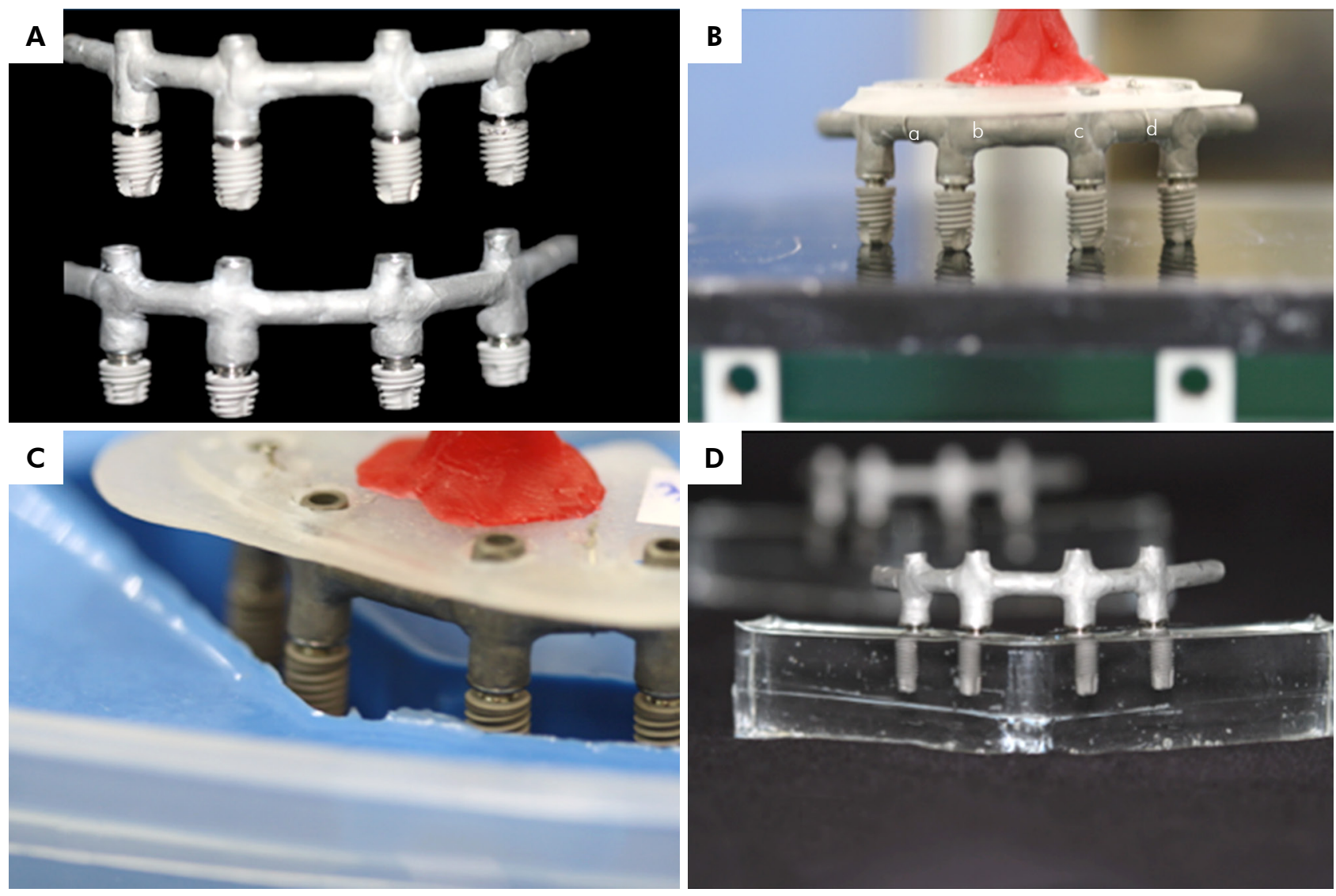

Figure 3. Photoelastic model: A) Implants, abutments and bar. B) Parallelism between the implants. C) The set inserted in the mold. D) Definitive model. 


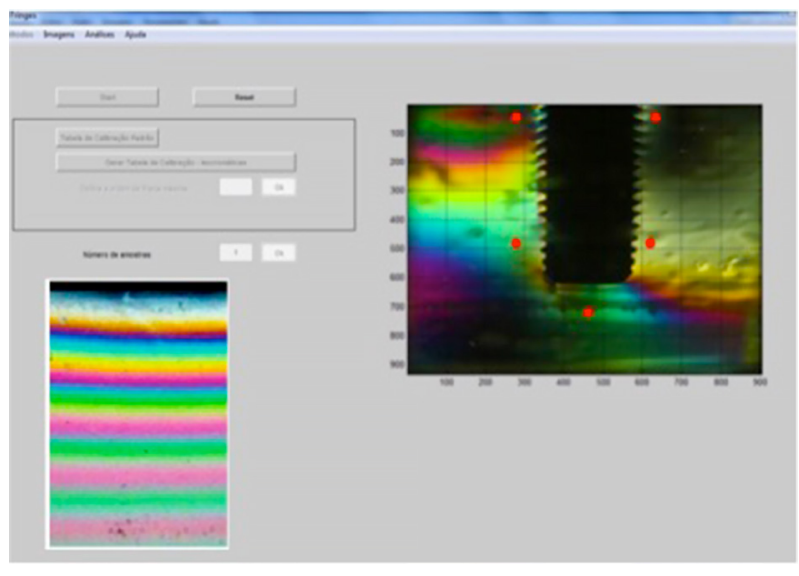

Figure 4. The Fringes Scale, Software platform and the predetermined points of analysis (red points)

\section{Results}

Qualitative analysis showed that the fringes were present mainly in the implant closer to the load side (implant $A$ ) and in the subsequent implant (implant $B$ ). Thus, only these two implants were analysed in the software (Table 2).

With regard to stress behavior in the cervical area, the 9-mm-long implants showed shear stress values similar to those found in the CG. Significant differences between CG and short implants ( 5 and $7 \mathrm{~mm}$ long) with regular diameter $(4 \mathrm{~mm})$ were observed $(\mathrm{p}<0.05)$. However, when the comparison between implants was associated with the increased diameter, it was observed a reduction in the stress values in the cervical region, without significant differences between short implants and CG $(p>0.05)$.
For apical area, Ci5 showed significantly different stress behaviour with more stress concentration. The association with increased diameter (Wi5) reduced stress values without significant differences compared to the CG (Table 2, Figure 5).

Analysis of the implant $B$ showed that the length or the diameter of the implants seemed not to interfere with the stress behaviour for cervical areas, however a significant difference concerning the apical stress concentration was noted between Ci5 and CG (Table 2, Figure 6).

\section{Discussion}

The hypothesis that short implants increase stress levels in the peri-implant area when used to support a fixed prosthesis in atrophic mandible was accepted. However, the stress behaviour was different among the different length of short implants. Although no absolute consensus has been reached for the term "short implant", most studies have labeled implants up to $10 \mathrm{~mm}$ long as "short", ${ }^{20,22}$ a concept considered in the present study. Implants of $5 \mathrm{~mm}$ in length were included in this study to simulate an extreme condition. Few studies were found to evaluate the effectiveness of extra-short implants. ${ }^{7,3,30}$

In a systematic review, Annibali et al. ${ }^{21}$ reported that the biomechanical rationale behind the use of short implants is that high stress values occur in the crestal portion, whereas very little stress is transferred to the apical region. This finding is in accord with that observed in the present study, considering the implant A (load side). The short implants showed

Table 2. Shear stress values ( $\mathrm{kgf}$ ) to implant $A$ (closer to the load side) and implant B (subsequent implant).

\begin{tabular}{lcccc}
\hline \multirow{2}{*}{ Groups } & \multicolumn{2}{c}{ Implant A } & \multicolumn{2}{c}{ Implant B } \\
\cline { 2 - 5 } CG & Cervical stress & Apical stress & Cervical stress & Apical stress \\
Ci9 & $46.3 \pm 9.1$ & $51.5 \pm 7.1$ & $19.9 \pm 0.8$ & $31.0 \pm 1.7$ \\
Ci7 & $59.0 \pm 9.1$ & $59.7 \pm 7.9$ & $17.9 \pm 0.6$ & $34.3 \pm 8.0$ \\
Ci5 & $64.5 \pm 9.0^{*}$ & $54.3 \pm 7.7$ & $19.4 \pm 1.4$ & $35.1 \pm 5.1$ \\
Wi9 & $68.1 \pm 11.7^{*}$ & $75.8 \pm 10.2^{*}$ & $20.3 \pm 1.9$ & $40.8 \pm 7.7^{*}$ \\
Wi7 & $54.2 \pm 6.5$ & $56.4 \pm 6.7$ & $20.2 \pm 1.0$ & $32.2 \pm 1.0$ \\
Wi5 & $57.4 \pm 8.8$ & $56.4 \pm 2.4$ & $18.9 \pm 2.0$ & $27.6 \pm 3.3$ \\
\hline CG: & $61.0 \pm 9.5$ & $57.3 \pm 4.5$ & $18.4 \pm 3.6$ & $30.4 \pm 6.3$ \\
\hline
\end{tabular}

CG: control group; Ci: conventional implant (4.0mm of diameter); Wi: wide implant (5.0 mm of diameter); ${ }^{*}$ different behavior compared to CG Comparisons significant at the 0.05 


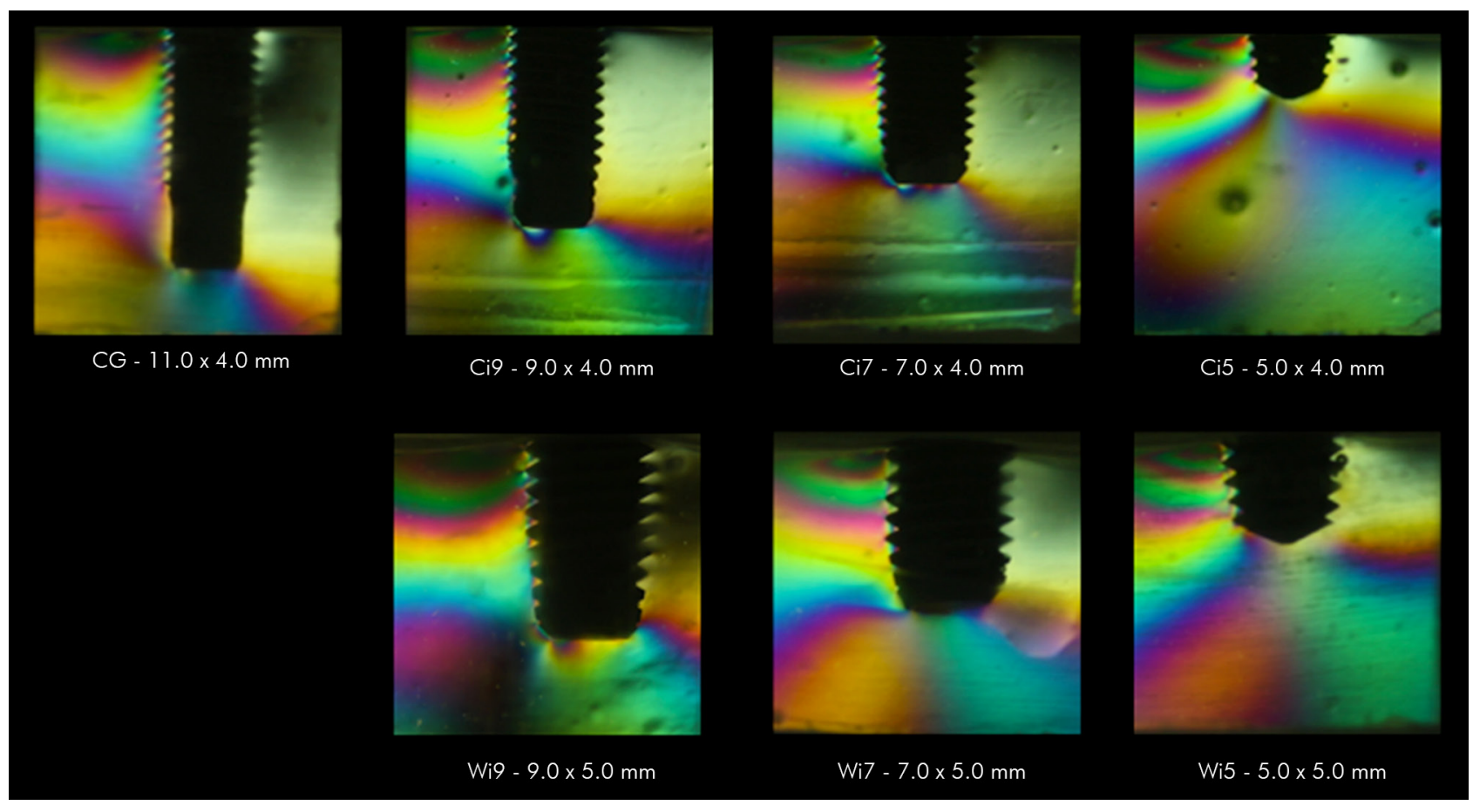

Figure 5. Illustration of the behaviour of fringes in the groups to implant $A$.

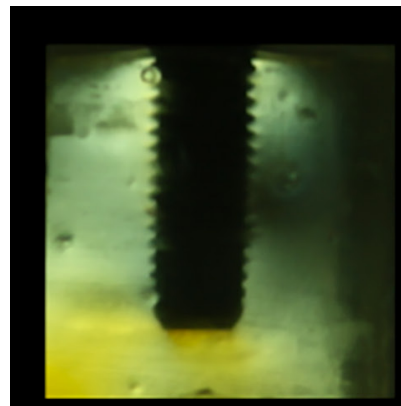

CG $-11.0 \times 4.0 \mathrm{~mm}$

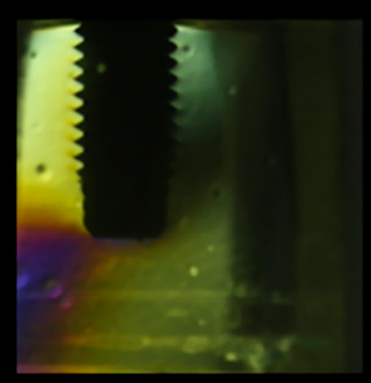

Ci9 $-9.0 \times 4.0 \mathrm{~mm}$

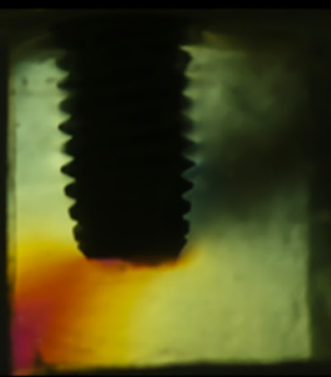

Wi9 $-9.0 \times 5.0 \mathrm{~mm}$

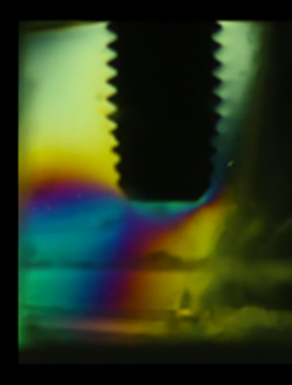

Ci7 $-7.0 \times 4.0 \mathrm{~mm}$

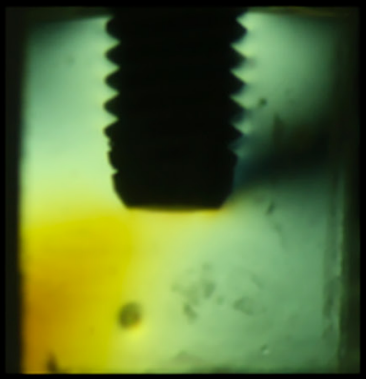

Wi7 $-7.0 \times 5.0 \mathrm{~mm}$

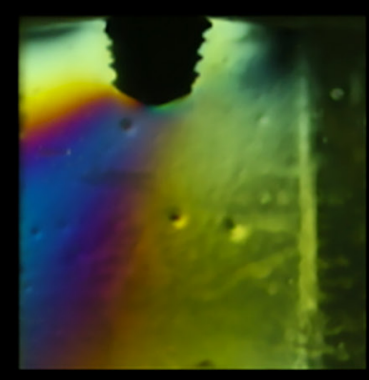

$\mathrm{Ci} 5-5.0 \times 4.0 \mathrm{~mm}$

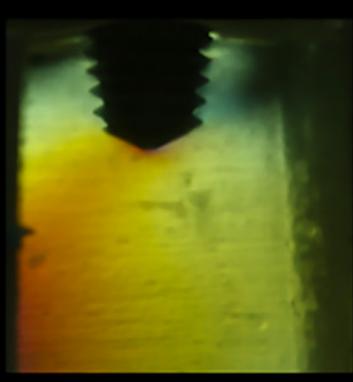

Wi5 - $5.0 \times 5.0 \mathrm{~mm}$

Figure 6. Illustration of the behaviour of fringes in the groups to implant B.

higher shear stress values in their cervical portion, and the images clearly show more fringes formation to short implants. The stress concentration observed for the implant A might be due to the site load in the cantilever extension; the stress was concentrated especially in the cervical portion in the same load 
side. Unlike A, the subsequent implant (B), showed higher concentration of stress in the apical region. This may result from the splint arrangement, since that the splints between the implants change the biomechanical behaviour. ${ }^{8,31,32}$ The other implants (C and D) showing no fringes formation, and for this reason, they were excluded from the quantitative analyses.

The length of the implants was initially associated with implant failure rates. ${ }^{11,12}$ However the survival rates of short implants must be compared with the success rate of long implants associated with advanced surgical techniques of graft, ${ }^{9,17,21}$ since that the short implants should be considered an alterative to eliminated grafts procedures. Under these circumstances, the survival of long implants decreases, and being recommended to prioritize simpler approaches. ${ }^{3,4}$ The present study found similar stress behaviour when long implant (11 mm) was compared to short/wide implants. However, long implant presented different behaviour when compared to short implants with regular diameter (Ci5 and Ci7). The reduction in the shear stress values when the increased diameter was associated, confirm that the contact area between bone-implant is relevant to improve the mechanical behaviour. ${ }^{25}$ However, the reduction in length did not result in statistical differences between short and long implants. A clinical retrospective study affirms that factors involving the survival rates seem to be independent of the implant length, and the prognosis of short implants is consistent to partial and single-crowns. ${ }^{15}$ However, this retrospective study compare implants with 8 and $10 \mathrm{~mm}$ of length, meanwhile some authors consider implants with $10 \mathrm{~mm}$ as a short implant. ${ }^{23}$

Stress levels in the bone tissue surrounding splinted implants showed markedly lower values when compared with single implants. ${ }^{33}$ Previous clinical study showed $100 \%$ of survival to implants and prosthesis supported by short implants $(<10 \mathrm{~mm})$, even after 10 years of follow up. The authors report that this very good outcome could be resulted from splinting implants. ${ }^{1}$ Reflecting about the high successful reports with short implants, even to single crowns, and considering that to a fixed complete prosthesis the implants are splinted, we believe that short implants can be used to atrophic complete edentulous jaw without system biomechanical damage. It is interesting when Lai et al. ${ }^{8}$ affirm that short implants (shorter than $8 \mathrm{~mm}$ ) are sufficient to support occlusal forces (without difference between 6 or $8 \mathrm{~mm}$ ) even when restored with unsplinted single crowns, because this reinforce the hypotheses that splinted implants can show even better results. Despite this, was reported that the most failures with short implants happens before the loading, exempting biomechanical factors of blame for this failure. ${ }^{21,22,23}$

Many studies report the use short implants $(\leq 10 \mathrm{~mm})$ with a considerable success, however the literature regarding survival rate of $\leq 7 \mathrm{~mm}$ is sparse. ${ }^{13}$ Despite this, a recent systematic review affirms that implants shorter than $7 \mathrm{~mm}$ can be placed successfully, in mandibular or maxilla. The majority of the studies included in this review associate short and wide implants. ${ }^{13}$ Previous biomechanical test showed that an increase of the implant diameter resulted in more homogeneous stress distribution and less stress concentration on the implants,,$^{27}$ besides minimize complications, ${ }^{25,26}$ and might guarantee the conservation of marginal peri-implant bone level. ${ }^{34}$ Short-wide implants provides an increased implant-bone contact area and could make a short implant comparable to a longer implant with a smaller diameter. ${ }^{1}$ In addition, previous clinical trials suggested that the potential role of the implant diameter for short implants should be investigated, since clinicians tend to compensate for the lack of height by using implants with a wider diameter. ${ }^{17}$ The present study brings some valuable information regarding this discussion showing that the association of short and wide diameter resulted in better performance for short implants $(9,7$ and $5 \mathrm{~mm})$ and approximates the biomechanical behaviour to those found with long implants. Considering the adjacent implant (B), shorter-wide implants (7 and $5 \mathrm{~mm}$ ) concentrated less stress in the peri-implant area than longer implant. This biomechanical testing proves that has a comparable behaviour between the short-wide implants and the long implants regarding the concentration of stress in the peri-implant area.

Interesting point to discuss is the possibility of a large diameter implant being compatible with bone-resorbed shape. Although considered 
large, implants with 5 and $6 \mathrm{~mm}$ of diameter were considered sufficiently small to allow rehabilitation of posterior jaw in severe resorbed cases. ${ }^{7,17}$ Short implant with $4.8 \mathrm{~mm}$ of diameter were reported to support fixed complete dentures without fractures or more complications. ${ }^{15}$ Although, this, some patients are successfully rehabilitated even with short-lower diameter implants (3.0 to 4.5$))^{1,13}$

Few study reported results with 6 or $5 \mathrm{~mm}$ implants length. Systematic review affirms that this point limits conclusions about their clinical outcomes that should be drawn with caution. ${ }^{21}$ The results of the present study reinforce the caution needed, since that implants with $5 \mathrm{~mm}$ showed different stress behaviour. Nevertheless, clinical studies conduced with extra short implants $(5 \times 5 \mathrm{~mm})$ concluded that, clinically, the short implants are similar, if not better, to the longer implants to single crown or partial restoration in short term follow up. .9,17 $^{2}$

Although there are surprising results with short implants, there are some precautions not yet discussed, such as the cantilevers avoidance. ${ }^{35}$ The success rate of implants restored with single crown and cantilevers restorations are lower than splinted fixed partial prosthesis. ${ }^{36}$ The present study produced a $15 \mathrm{~mm}$ of cantilever, and even in this condition the results of short implants were similar to long implant. This may be due the splinting multiple implants, that is considered is favourable to improve the biomechanical behaviour ${ }^{33,35}$ and survival ${ }^{36}$ of the implants.

The predictable use of short implants could expand the indications and increase patient acceptance of the implant therapy. ${ }^{8}$ However, there are relevant points were not analized in this study, such as the behaviour of the prosthetics components (abutments, bar and retention screw), the stress concentration on implant body and the quality of remain bone in severe atrophic conditions. The use of short implant is indicate for severe bone loss, and this is totally related with prosthetic height to restore the facial vertical dimension, The presence of the bar can simulate the behaviour of fixed denture and identify the real influence of implant height without the different prosthetic heights between the groups. The bone quality can influence the survival rates. ${ }^{1}$ It was not considered in this study, however concern that the bone type seems similar to long implants, short implants had a better prognosis in the mandible, ${ }^{20}$ as well in the bone type I - III ${ }^{8}$ witch specially caution to bone type $\mathrm{IV},{ }^{25,37}$ that is no frequently observed in mandible.

\section{Conclusion}

Short implants increased stress concentration around the implant especially in the cervical portion. Wide short implants showed similar behaviour to the long implants while implants with 5 and $7 \times 4 \mathrm{~mm}$ increase the stress level around analysed implants.

\section{Acknowledgments}

The authors would like to thank Professor Mauro A. A. Nobilo for allowing use of a polariscope for this study, and Professor Marcelo F. Mesquita for allowing use of the prosthesis laboratory at the Piracicaba Dental School. Supported by grant No. \#2011/21877-2 from Sao Paulo Research Fundation (FAPESP).

\section{References}

1. Mertens C, Meyer-Bäumer A, Kappel H, Hoffmann J, Steveling HG. Use of 8-mm and 9-mm implants in atrophic alveolar ridges:10-year results. Int J Oral Maxillofac Implants. 2012;27(6):1501-8.

2. Yi YS, Emanuel KM, Chuang SK. Short $(5.0 \times 5.0 \mathrm{~mm})$ implant placements and restoration with integrated abutment crowns. Implant Dent. 2011;20(2):125-30. http://doi.org/10.1097/ID.0b013e31820fb67e
3. Chiapasco M, Casentini P, Zaniboni M. Bone augmentation procedures in implant dentistry. Int J Oral Maxillofac Implants. 2009;24 Suppl:237-59.

4. Chiapasco M, Zaniboni M, Boisco M. Augmentation procedures for the rehabilitation of deficient edentulous ridges with oral implants. Clin Oral Implants Res. 2006;17(Suppl 2):136-59. http://doi.org/10.1111/j.1600-0501.2006.01357.x 
5. Guljé F, Abrahamsson I, Chen S, Stanford C, Zadeh H, Palmer R. Implants of $6 \mathrm{~mm}$ vs. $11 \mathrm{~mm}$ lengths in the posterior maxilla and mandible:a 1-year multicenter randomized controlled trial. Clin Oral Implants Res. 2013;24(12):1325-31. http://doi.org/10.1111/clr.12001

6. Arlin ML. Short dental implants as a treatment option: results from an observational study in a single private practice. Int J Oral Maxillofac Implants. 2006;21(5):769-76.

7. Felice P, Pistilli R, Piattelli M, Soardi E, Corvino V, Esposito M. Posterior atrophic jaws rehabilitated with prostheses supported by $5 \times 5 \mathrm{~mm}$ implants with a novel nanostructured calcium-incorporated titanium surface or by longer implants in augmented bone: preliminary results from a randomised controlled trial. Eur J Oral Implantol. 2012;5(2):149-61.

8. Lai HC, Si MS, Zhuang LF, Shen H, Liu YL, Wismeijer D. Long-term outcomes of short dental implants supporting single crowns in posterior region:a clinical retrospective study of 5-10 years. Clin Oral Implants Res. 2013;24(2):230-7. http://doi.org/10.1111/j.1600-0501.2012.02452.x

9. Esposito M, Cannizarro G, Soardi E, Pellegrino G, Pistilli R, Felice P. A 3-year post-loading report of a randomised controlled trial on the rehabilitation of posterior atrophic mandibles: short implants or longer implants in vertically augmented bone? Eur J Oral Implantol. 2011;4(4):301-11.

10. Felice P, Pellegrino G, Checchi L, Pistilli R, Esposito M. Vertical augmentation with interpositional blocks of anorganic bovine bone vs. 7-mm-long implants in posterior mandibles:1-year results of a randomized clinical trial. Clin Oral Implants Res. 2010;21(12):1394-403. http://doi.org/10.1111/j.1600-0501.2010.01966.x

11. Jemt $T$. Failures and complications in 391 consecutively inserted fixed prostheses supported by Brånemark implants in edentulous jaws: a study of treatment from the time of prosthesis placement to the first annual checkup. Int J Oral Maxillofac Implants. 1991;6(3):270-6.

12. Lekholm U, Gunne J, Henry P, Higuchi K, Lindén U, Bergström C et al. Survival of the Brånemark implant in partially edentulous jaws:a 10-year prospective multicenter study. Int J Oral Maxillofac Implants. 1999;14(5):639-45.

13. Karthikeyan I, Desai SR, Singh R. Short implants: a systematic review. J Indian Soc Periodontol. 2012;16(3):302-12. http://doi.org/10.4103/0972-124X.100901

14. Perelli M, Abundo R, Corrente G, Saccone C. Short (5 and $7 \mathrm{~mm}$ long) porous implant in the posterior atrophic mandible: a 5-year report of a prospective study. Eur J Oral Implantol. 2011;4(4):363-8.

15. Lops D, Bressan E, Pisoni G, Cea N, Corazza B, Romeo E. Short implants in partially edentuolous maxillae and mandibles:a 10 to 20 years retrospective evaluation. Int J Dent. 2012;2012:351793. http://doi.org/10.1155/2012/351793

16. Jiansheng $H$, Dongying $X$, Xianfeng W, Baoyi $X$, Qiong L, Jincai Z. Clinical evaluation of short and wide-diameter implants immediately placed into extraction sockets of posterior areas: a 2-year retrospective study. J Oral Implantol. 2012;38(6):729-37. http://doi.org/10.1563/AAID-JOI-D-11-00168

17. Esposito M, Pellegrino G, Pistilli R, Felice P. Rehabilitation of postrior atrophic edentulous jaws: prostheses supported by $5 \mathrm{~mm}$ short implants or by longer implants in augmented bone? One-year results from a pilot randomised clinical trial. Eur J Oral Implantol. 2011;4(1):21-30.

18. Felice P, Checchi V, Pistilli R, Scarano A, Pellegrino G, Esposito M. Bone augmentation versus 5-mm dental implants in posterior atrophic jaws. Four-month post-loading results from a randomised controlled clinical trial. Eur J Oral Implantol. 2009;2(4):267-81.

19. Stellingsma K, Raghoebar GM, Meijer HJ, Stegenga B. The extremely resorbed mandible: a comparative prospective study of 2-year results with 3 treatment strategies. Int J Oral Maxillofac Implants. 2004;19(4):563-77.

20. Telleman G, Raghoebar GM, Vissink A, Hartog L, Huddleston Slater JJR, Meijer HJ. A systematic review of the prognosis of short ( $<10 \mathrm{~mm}$ ) dental implants placed in the partially edentulous patient. J Clin Periodontol. 2011;38(7):667-76. http://doi.org/10.1111/j.1600-051X.2011.01736.x

21. Annibali S, Cristalli MP, Dell'Aquila D, Bignozzi I, La Monaca G, Pilloni A. Short dental implants: a systematic review. J Dent Res. 2012;91(1):25-32. http://doi.org/10.1177/0022034511425675

22. Atieh MA, Zadeh H, Stanford CM, Cooper LF. Survival of short dental implants for treatment of posterior partial edentulism:a systematic review. Int J Oral Maxillofac Implants. 2012;27(6):1323-31.

23. Menchero-Cantalejo E, Barona-Dorado C, Cantero-Álvarez M, Fernández-Cáliz F, Martínez-González JM. Meta-analysis on the survival of short implants. Med Oral Patol Oral Cir Bucal. 2011;16(4):e546-51. http://doi.org/10.4317/medoral.16.e546

24. Feldman S, Boitel N, Weng D, Kohles SS, Stach RM. Five-year survival distributions of short-length (10 mm or less) machined-surfaced and Osseotite implants. Clin Implant Dent Relat Res. 2004;6(1):16-23. http://doi.org/10.1111/j.1708-8208.2004.tb00023.x

25. Renouard F, Nisand D. Impact of implant length and diameter on survival rates. Clin Oral Implants Res. 2006;17(Suppl 2):35-51. http://doi.org/ 10.1111/j.1600-0501.2006.01349.x

26. Neves FD, Fones D, Bernardes SR, Prado CJ, Fernandes Neto AJ. Short implants: an analysis of longitudinal studies. Int J Oral Maxillofac Implants. 2006;21(1):86-93. http://doi.org/10.1016/j.prosdent.2006.05.023

27. Paula GA, Mota AS, Moreira AN, Magahlães CS, Cornacchia TPM, Cimini CA. The effect of prosthesis length and implant diameter on the stress distribution in tooth-implant-supported prostheses:a finite element analysis. Int J Oral Maxillofac Implants. 2012;27(3):e19-28. 
28. Stellingsma C, Vissink A, Meijer HJA, Kuiper C, Raghoebar GM. Implantology and the severely resorbed edentulous mandible. Crit Rev Oral Biol Med. 2004;15(4):240-248. http://doi.org/10.1177/154411130401500406

29. Soehardi A, Meijer GJ, Manders R, Stoelnga PJW. An inventory of mandibular fractures associated with implants in atrophic edentulous mandibles: a survey of Dutch oral and maxillofacial surgeons. Int J Oral Maxillofac Implants. 2011;26(5):1087-93.

30. Bressan E, Sivolella S, Urrutia ZA, Salata LA, Lang $\mathrm{NP}$, Botticelli D. Short implants $(6 \mathrm{~mm})$ installed immediately into extraction sockets: an experimental study in dogs. Clin Oral Implants Res. 2012;23(5):536-41. http://doi.org/10.1111/j.1600-0501.2012.02432.x

31. Pjetursson BE, Tan K, Lang NP, Brägger U, Egger $\mathrm{M}$, Zwahlen M. A systematic review of the survival and complication rates of fixed partial dentures (FPDs) after an observation period of at least 5 years. Clin Oral Implants Res. 2004;15(6):667-76. http://doi.org/10.1111/j.1600-0501.2004.01120.x

32. Nissan J, Ghelfan O, Gross M, Chaushu G. Analysis of load transfer and stress distribution by splinted and unsplinted implant-supported fixed cemented restorations. J Oral Rehabil. 2010;37(9):658-62. http://doi.org/10.1111/j.1365-2842.2010.02096.x
33. Bergkvist G, Simonsson K, Rydberg K, Johansson F, Dérand T. A finite element analysis of stress distribution in bone tissue surrounding uncoupled or splinted dental implants. Clin Implant Dent Relat Res. 2008;10(1):40-6. http://doi.org/10.1111/j.1708-8208.2007.00059.x

34. Sbordone C, Toti P, Ramaglia L, Guidetti F, Sbordone L, Martuscelli R. A 5-year clinical and computerized tomographic implant follow-up in sinuslifted maxillae and native bone. Clin Oral Implants Res. 2014;25(9):1056-64. http://doi.org/10.1111/clr.12222

35. Misch CE, Steignga J, Barboza E, Misch-Dietsh F, Cianciola LJ, Kazor C. Short dental implants in posterior partial edentulism: a multicenter retrospective 6-year case series study. J Periodontol. 2006;77(8):1340-7. http://doi.org/10.1902/jop.2006.050402

36. De Santis D, Cucchi A, Longhi C, Vincenzo B. Short threaded implants with an oxidized surface to restore posterior teeth:1- to 3-year results of a prospective study. Int J Oral Maxillofac Implants. 2011;26(2):393-403.

37. Nedir R, Bischof M, Briaux JM, Beyer S, Szmukler-Moncler S, Bernard J-P. A 7-year life table analysis from a prospective study on ITI implants with special emphasis on the use of short implants: results from a private practice. Clin Oral Implants Res. 2004;15(2):150-7. http://doi.org/10.1111/j.1600-0501.2004.00978.x 